Article

\title{
Reactive Sputtering Deposition of Epitaxial TiC Film on Si (100) Substrate
}

\author{
Yu-Siang Fang ${ }^{1, *}$, Thi Hien Do ${ }^{1}$, Kun-An Chiu ${ }^{1}$, Wei-Chun Chen ${ }^{2}$ and Li Chang ${ }^{1, *}$ \\ 1 Department of Materials Science and Engineering, National Chiao Tung University, Hsinchu 30010, Taiwan; \\ dohienvl@gmail.com (T.H.D.); j73628.mse95g@nctu.edu.tw (K.-A.C.) \\ 2 Taiwan Instrument Research Institute, National Applied Research Laboratories, Hsinchu 30076, Taiwan; \\ weichun@tiri.narl.org.tw \\ * Correspondence: lacus830618@gmail.com (Y.-S.F.); lichang@cc.nctu.edu.tw (L.C.); \\ Tel.: +886-3-5712121 (ext. 55373) (L.C.); Fax: +886-3-5724727 (L.C.)
}

Received: 9 June 2020; Accepted: 3 July 2020; Published: 5 July 2020

\begin{abstract}
Epitaxial (100) TiC film deposition on Si (100) substrate by direct current magnetron reactive sputtering of a metallic Ti target with $3 \%-6 \% \mathrm{CH}_{4}$ in Ar gas was investigated. X-ray diffraction and cross-sectional scanning transmission electron microscopy (STEM) reveal that epitaxial cubic TiC can be grown on the Si substrate by domain matching epitaxy in 5/4 ratio with the epitaxial relationship of $\mathrm{TiC}(100)[0 \overline{1} 1] / / \mathrm{Si}(100)[0 \overline{1} 1]$. For sputtering with $3 \%$ and $4 \% \mathrm{CH}_{4}$, the deposited films are found to consist of both TiC and metallic Ti phases. Increasing the $\mathrm{CH}_{4}$ flow ratio to $5 \%$ results in a deposited film completely consisting of $\mathrm{TiC}$ without metallic Ti phase. The crystallinity of the deposited TiC is also improved with increasing the $\mathrm{CH}_{4}$ ratio to $5 \%$. X-ray photoelectron spectroscopy shows that the $[\mathrm{C}] /[\mathrm{Ti}]$ atomic ratio in $\mathrm{TiC}$ is nearly close to 1 for growth with $5 \% \mathrm{CH}_{4}$ flow ratio and above. The measured electrical resistivities of the deposited films also increase from 41 to $153 \mu \Omega \cdot \mathrm{cm}$ with increasing the $\mathrm{CH}_{4}$ ratio from 3\% to $6 \%$. With film growth beyond $50 \mathrm{~nm}$ thickness, it is shown that some disoriented $\mathrm{TiC}$ grains are formed.
\end{abstract}

Keywords: $\mathrm{TiC}$; Si substrate; epitaxial growth; reactive magnetron sputtering

\section{Introduction}

Titanium carbide ( $\mathrm{TiC}$ ), as one of the transition metal carbides, has excellent properties such as high melting point, high hardness, low resistivity, high thermal stability, and chemical inertness, as well as good resistance to corrosion and oxidation [1,2]. TiC has a rock salt structure $(a=4.328 \AA)$ and maintains its structure in an extremely broad range of composition $\left(\mathrm{TiC}_{x}, 0.47 \leq x \leq 0.99\right)$ [1-3]. Owing to those superior properties, polycrystalline TiC films can be used as wear-resistant coating, passive layers, electrodes, field emission cathodes, and metal contact for semiconductor devices [4-10]. Moreover, applications for epitaxial TiC in the field of high power electronic devices, buffer layers, and seeding layers have been recently reported [11-15].

TiC coatings have been prepared by physical vapor deposition and chemical vapor deposition processes, including magnetron sputtering, pulsed laser deposition, evaporation, and plasma-assisted chemical vapor deposition [16-21]. Among these methods, reactive sputtering has several advantages such as high deposition rate, low impurity content, and it has been widely used for cost-effective industrial production [22].

To obtain epitaxial $\mathrm{TiC}$ films, single crystals of $\mathrm{MgO}, \mathrm{SiC}$, and $\mathrm{Al}_{2} \mathrm{O}_{3}$ which are expensive in large area have been used as substrates $[14,17,18,20,23]$. However, Si wafers which are easily available in large size with low cost may be able to be used as the substrate for epitaxial growth of TiC to extend its applications in many fields. Even though the lattice mismatch between $\mathrm{TiC}$ and $\mathrm{Si}$ is $\sim 20 \%$ which is 
much larger than that for conventional heteroepitaxy which requires a small value usually less than $9 \%$, it is still possible for epitaxial growth of $\mathrm{TiC}$ on Si by domain matching epitaxy (DME) as already demonstrated in many material systems such as TiN on Si [24].

Epitaxial growth of $\mathrm{TiC}$ films by reactive magnetron sputtering at relatively high temperature may be beneficial for obtaining high crystalline film quality $[18,23]$. However, epitaxial growth of $\mathrm{TiC}$ on $\mathrm{Si}$ substrate by reactive magnetron sputtering, as well as the influence of $\mathrm{CH}_{4}$ flow ratio, has rarely been reported in the literatures [25]. For growth of epitaxial TiC on $\mathrm{Si}$ at higher temperature, a few issues have to be addressed such as $\mathrm{SiC}$ formation in competition with $\mathrm{TiC}$ under carbon-rich conditions in addition to the reaction of Ti with $\mathrm{Si}$ to form silicides or Ti-Si-C compound above $1000{ }^{\circ} \mathrm{C}$ [26-28]. Also, it is known that the formation of graphite and amorphous $\mathrm{C}$ may occur by reactive sputtering with carbon-containing gas in high concentration [29].

In this study, we present the results of heteroepitaxial growth of TiC film on $\mathrm{Si}$ (100) substrates by reactive magnetron sputtering at high deposition temperature. The influence of the $\mathrm{CH}_{4}$ flow ratio on crystalline quality, surface morphology, elemental composition, and electrical resistivity of TiC film on $\mathrm{Si}$ is investigated. Also, the characteristics of the TiC/Si interface and the evolution of film microstructure with thickness are presented.

\section{Material and Methods}

TiC films were deposited on $1 \times 1 \mathrm{~cm}^{2}$ p-type (100) Si substrates by reactive direct current (DC) magnetron sputtering of a metallic Ti target in a discharge of $\mathrm{Ar}\left(99.9999 \%\right.$ purity) and $\mathrm{CH}_{4}$ ( $99.999 \%$ purity) atmosphere. The Ti target of $99.995 \%$ purity (Summit-Tech, Taiwan) was fabricated from vacuum melting technique and had a disk shape in a size of 2 inches in diameter and $6 \mathrm{~mm}$ thickness. The Si substrates were cut from 6 inch p-type Si (100) wafers in $600 \mu \mathrm{m}$ thickness $(1-5 \Omega \cdot \mathrm{cm}$ resistivity). The substrates were cleaned in ultrasonic baths of acetone, methanol, and ethanol. The Si surface oxide layer was removed by using a $6 \%$ hydrofluoric acid aqueous solution, followed by blown dry with dry $\mathrm{N}_{2}$ gas before placing it into the vacuum chamber. After evacuation to a pressure $<2.66 \times 10^{-4} \mathrm{~Pa}$, the stage was heated to $870^{\circ} \mathrm{C}$ for $30 \mathrm{~min}$ to reduce the residual gas contamination in the chamber.

Prior to deposition, pre-sputtering of the Ti target was first carried out with pure Ar plasma to remove any surface contamination, and a clean vacuum condition was consequently obtained due to the gettering effect of sputtered Ti atoms. The gas mixture of $\mathrm{CH}_{4}$ and $\mathrm{Ar}$ was then used for sputtering, and the flow ratio of $\mathrm{CH}_{4} /\left(\mathrm{Ar}+\mathrm{CH}_{4}\right)$ was varied from $3 \%$ to $6 \%$ (hereinafter referred to as " $\mathrm{CH}_{4}$ flow ratio" or " $\mathrm{CH}_{4}$ ratio"). The deposition time for all conditions was $15 \mathrm{~min}$, and an additional sample was prepared in the condition for $5 \% \mathrm{CH}_{4}$ and $6 \mathrm{~min}$. The working pressure was maintained at $0.4 \mathrm{~Pa}$. For all the sputtering conditions, the distance between the Ti target and Si substrate was set at $6 \mathrm{~cm}$, the applied DC power was fixed at $50 \mathrm{~W}$, and the deposition temperature was $870{ }^{\circ} \mathrm{C}$.

Structural properties of the deposited films were investigated with X-ray diffraction (XRD) (D8 DISCIVER, BRUKER, Billerica, MA, USA). For general XRD characterization, $\mathrm{Cu} K \alpha$ radiation was used for $2 \theta-\omega$ scan with step size of $0.02^{\circ}$, in-plane scan with $0.002^{\circ}$, and $\phi$-scan with $0.5^{\circ}$. For high-resolution XRD, monochromatic X-ray of $\mathrm{Cu} \mathrm{K} \alpha_{1}$ was used for $2 \theta-\omega$ and $\omega$ (X-ray rocking curve) scans with step size of $0.002^{\circ}$. Surface morphologies of the deposited films were examined with scanning electron microscopy (SEM) (JSM-7800F Prime, JEOL, Akishima, Tokyo, Japan). X-ray photoelectron spectroscopy (XPS) (PHI QuanteraII, ULVAC-PHI, Chigasaki, Kanagawa, Japan) with a monochromatic $\mathrm{Al} \mathrm{K} \alpha$ radiation source was used to determine chemical compositions. Electrical resistivities of the deposited films were measured by using four-point probe. Microstructural characterization of the films was examined with cross-sectional transmission electron microscopy (TEM) and scanning transmission electron microscopy (STEM) (ARM200F, JEOL, Akishima, Tokyo, Japan) at $200 \mathrm{kV}$. Cross-sectional TEM specimens were prepared by $\mathrm{Ga}^{+}$focused ion beam (FIB) (NX2000, HITACHI, Chiyoda, Tokyo, Japan). 


\section{Results and Discussion}

\subsection{Influence of the $\mathrm{CH}_{4}$ Flow Ratio on Film Characteristics}

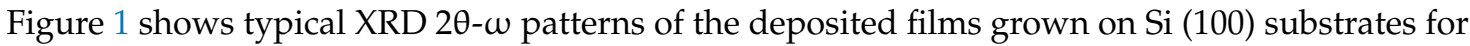
15 min with the $\mathrm{CH}_{4}$ flow ratio varying from $3 \%$ to $6 \%$. The diffraction peaks identified at $2 \theta$ values $\sim 41.7^{\circ}$ and $\sim 90.8^{\circ}$ are corresponding to $\mathrm{TiC} 200$ and $\mathrm{TiC} 400$ reflections, respectively [30], in addition to Si 400 at $69.129^{\circ}$. The additional peak at $40.17^{\circ}$ which is only observed for the $\mathrm{CH}_{4}$ flow ratio of $3 \%$ and $4 \%$ is from $10 \overline{1} 1$ reflection of hexagonal-close-packed (hcp) Ti. While the intensity of the Ti (10 $\overline{1} 1)$ peak decreases with the $\mathrm{CH}_{4}$ flow ratio, the TiC (200) peak is seen to have an increased intensity. The results suggest that more $\mathrm{C}$ atoms may be available for reaction with Ti to form TiC when the $\mathrm{CH}_{4}$ flow ratio is increased.

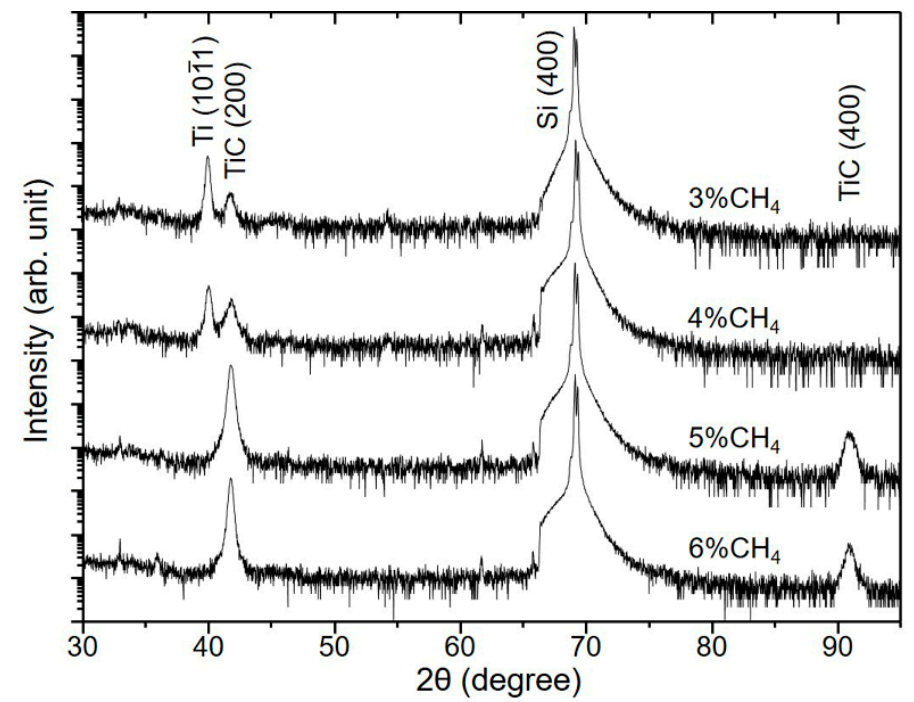

Figure 1. X-ray diffraction (XRD) 2 $\theta-\omega$ patterns of TiC films deposited on Si (100) substrates for different $\mathrm{CH}_{4}$ flow ratios.

As the XRD patterns show that TiC in each deposited film only exhibits 200 and 400 reflections, the deposited $\mathrm{TiC}$ is obviously in $<100>$ orientation on (100) Si substrate. XRD $\phi$-scans of all the TiC films deposited on Si (100) substrate were then performed with Si 311 and TiC 311 reflections to determine the orientation relationship of TiC with $\mathrm{Si}$. All the $\phi$-scan patterns of the TiC films exhibit the same characteristics as typically shown in Figure 2 obtained from the condition with $5 \% \mathrm{CH}_{4}$. Each pattern shows four peaks separated by $90^{\circ}$ at the same $\phi$ angles for both $\mathrm{TiC}$ and $\mathrm{Si}$, indicating that $\mathrm{TiC}$ is in epitaxy with Si. The orientation relationship is shown to be TiC (100)[0̄11] // Si (100)[011].

Figure 3a shows the variation of the TiC (200) X-ray rocking curves (XRC) with $\mathrm{CH}_{4}$ flow ratio from which the full width at half maximum (FWHM) for $3 \%, 4 \%, 5 \%$, and $6 \% \mathrm{CH}_{4}$ is $3.81^{\circ}, 3.44^{\circ}, 1.66^{\circ}$, and $2.24^{\circ}$, respectively, as plotted in Figure $3 \mathrm{~b}$. The FWHM results suggest that the crystalline quality of $\mathrm{TiC}$ may be improved with increasing $\mathrm{CH}_{4}$ flow ratio.

For the samples deposited with $5 \%$ and $6 \% \mathrm{CH}_{4}$, the peak position of $\mathrm{TiC} 200$ reflection from high resolution $\mathrm{XRD}$ is at the $2 \theta$ value of $41.766^{\circ}$ and $41.780^{\circ}$, respectively, and for $\mathrm{TiC} 400$ reflection at the $2 \theta$ value of $90.907^{\circ}$ and $90.982^{\circ}$ after calibration with $\mathrm{Si} 004$ peak from $\mathrm{Cu} \mathrm{K} \alpha_{1} \mathrm{X}$-ray. From those $2 \theta$ values with the corresponding interplanar spacings determined from the Bragg's law, the out-of-plane $\left(a_{\perp}\right)$ lattice parameter is $4.323 \pm 0.001 \AA$ for $5 \% \mathrm{CH}_{4}$ and $4.321 \pm 0.001 \AA$ for $6 \% \mathrm{CH}_{4}$, showing that it shifts to a slightly lower value with $\mathrm{CH}_{4}$ flow ratio. In order to determine the relaxed lattice constant $\left(a_{\mathrm{o}}\right)$, in-plane diffraction of $\mathrm{TiC} 022$ reflection has been carried out to deduce the in-plane $\left(a_{\|}\right)$lattice parameter. To perform in-plane diffraction scan, the samples were tilted to a $\chi$ angle of $89^{\circ}, 2 \theta$ and $\omega$ angles were aligned with Si 022 reflections from $\mathrm{Cu} \mathrm{K} \alpha_{1}$ and $K \alpha_{2}$ X-rays. After the alignment procedure, $2 \theta-\omega$ scans were performed from $45^{\circ}$ to $65^{\circ}$ to obtain TiC 022 reflection as shown in Figure 4 . 


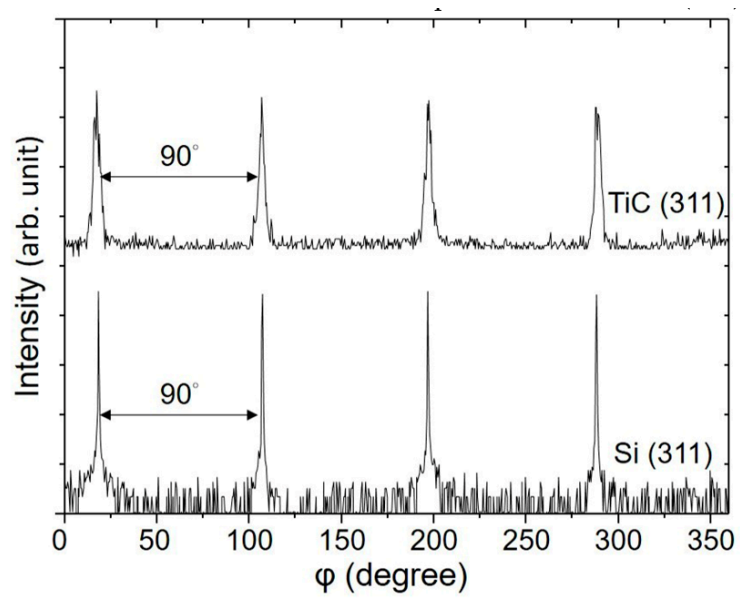

Figure 2. XRD $\varphi$-scan patterns of TiC 311 and $\mathrm{Si} 311$ reflections for $5 \% \mathrm{CH}_{4}$.

a

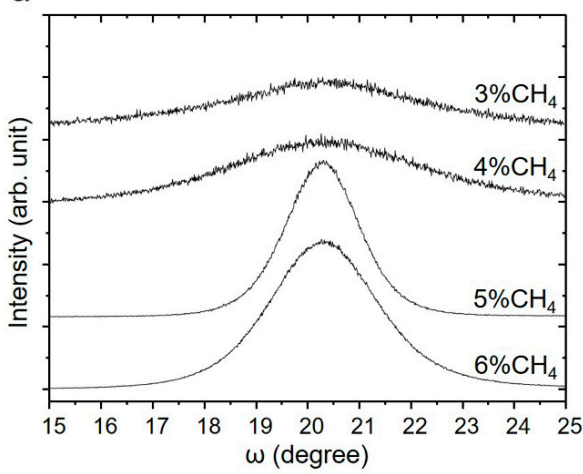

b

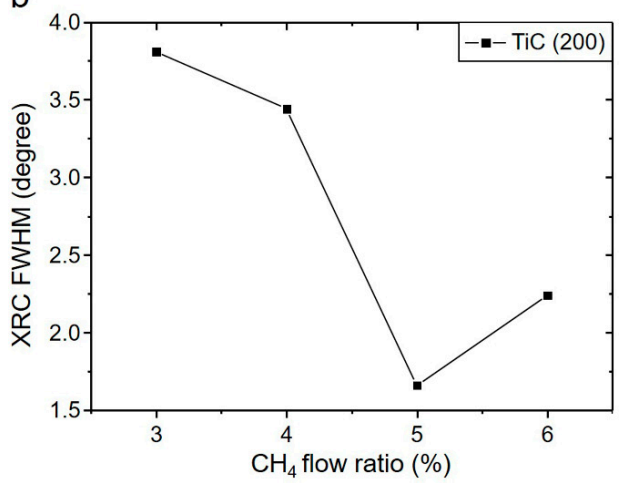

Figure 3. (a) X-ray rocking curves (XRC) of TiC 200 reflection for different $\mathrm{CH}_{4}$ flow ratios and (b) variation of the XRC full width at half maximum (FWHM) with $\mathrm{CH}_{4}$ flow ratio.

a

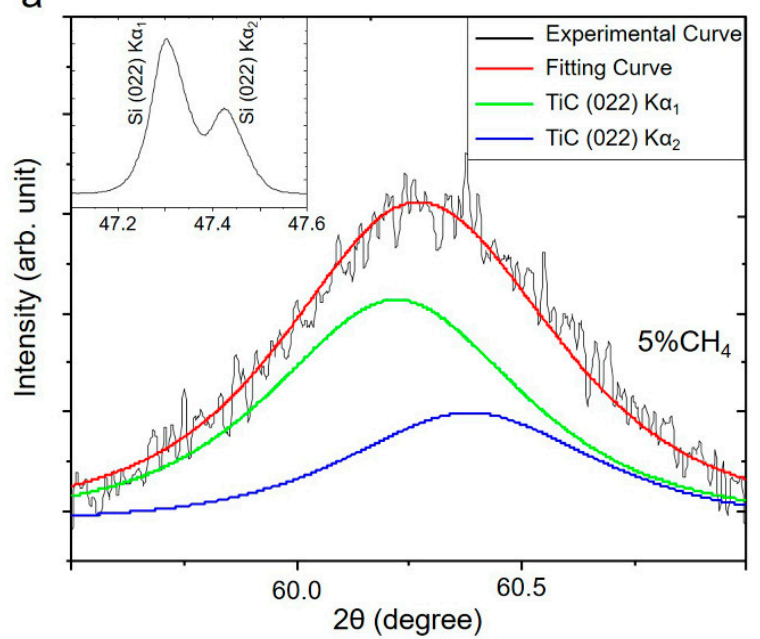

b

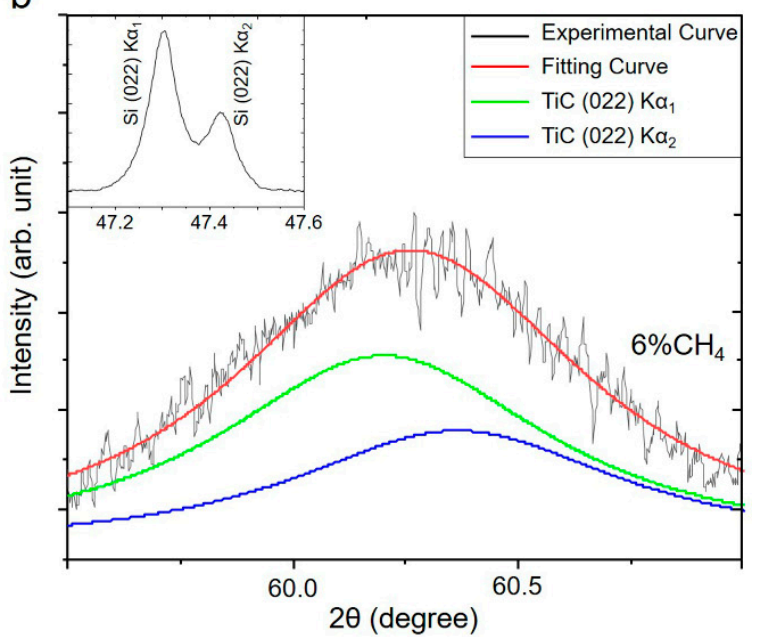

Figure 4. In-plane XRD 2 $\theta-\omega$ patterns of TiC 022 reflection with inset showing the corresponding pattern of Si 022 reflection. (a) $5 \% \mathrm{CH}_{4}$ and (b) $6 \% \mathrm{CH}_{4}$. Curve fitting showing the peaks of TiC from $\mathrm{Cu} \mathrm{K} \alpha_{1}$ and $\mathrm{K} \alpha_{2}$ X-rays in a 2/1 ratio for the corresponding integrated intensity.

As can be seen, the $\mathrm{TiC}$ peak appears almost at the same $2 \theta$ angle in both in-plane patterns within experimental error after calibration with Si peaks. Also, the corresponding interplanar spacing of TiC (022) can be obtained after curve fitting to deconvolute the contribution from $\mathrm{Cu} \mathrm{K} \alpha_{1}$ and $\mathrm{K} \alpha_{2} \mathrm{X}$-rays. 
Thus, the in-plane $\left(a_{\|}\right)$lattice parameter is determined to be $4.343 \pm 0.002 \AA$ for both $5 \%$ and $6 \% \mathrm{CH}_{4}$ cases. For a cubic structure, the relaxed lattice parameter, $a_{0}$, can be determined from Equation (1) [31]

$$
a_{0}=a_{\perp}\left(1-\frac{2 v\left(a_{\perp}-a_{\|}\right)}{a_{\perp}(1+v)}\right)
$$

where $v$ is the Poisson's ratio, and the equation can be derived by Formula (1.23) in [32]. From the literature, 0.19 is used for $v$ [1]. After substituting the values of $a_{\perp}$ and $a_{\|}$into Equation (1), $a_{\mathrm{o}}$ is calculated to be 4.329 and $4.328 \AA$ for $5 \%$ and $6 \% \mathrm{CH}_{4}$ samples, respectively. It is known that $\mathrm{TiC}_{x}$ is a substoichiometric compound with $x \leq 0.99$ as illustrated in the equilibrium Ti-C binary phase diagram, and its lattice parameter decreases with increased $x$ in the range of $0.85 \leq x \leq 0.99$ [1]. Hence, the lattice parameter of $4.329 \AA$ for $\mathrm{TiC}_{x}$ may correspond to $x=0.96$, and the value of $4.328 \AA$ for $x=0.99$. For sputtering with $6 \% \mathrm{CH}_{4}$ condition, it may be reasonable for the $\mathrm{TiC}$ film to be enriched with $\mathrm{C}$, i.e., $x$ is closer to 1 in comparison with the $5 \% \mathrm{CH}_{4}$ condition which has less $\mathrm{C}$ available during sputtering. Also, the slightly smaller TiC lattice parameter for the $6 \% \mathrm{CH}_{4}$ sample leads to a larger deviation from the 5/4 DME ratio between TiC and Si $[(4.328 \times 5) /(5.431 \times 4)=0.9961$ is further away from 1 than $(4.329 \times 5) /(5.431 \times 4)=0.9964]$, such that it may result in a lower film quality as shown with a larger XRC FWHM value than that for $5 \% \mathrm{CH}_{4}$.

SEM micrographs as shown in Figure 5 reveal the surface morphology for different $\mathrm{CH}_{4}$ flow ratios. With increasing the $\mathrm{CH}_{4}$ ratio, the coalescence of the film is more complete with a smooth surface morphology without cavities. The film thickness determined by cross-sectional SEM observations for $3 \%, 4 \%, 5 \%$, and $6 \% \mathrm{CH}_{4}$ ratio is $246,167,130$, and $148 \mathrm{~nm}$, respectively (not shown). The thickness significantly reduces from $246 \mathrm{~nm}$ to $130 \mathrm{~nm}$ when the $\mathrm{CH}_{4}$ ratio is increased from $3 \%$ to $5 \%$. Further increasing the $\mathrm{CH}_{4}$ ratio to $6 \%$ slightly increases the thickness. For the decrease of the deposition rate with $\mathrm{CH}_{4}$ ratio (3\% to $5 \%$ ), it can be reasoned with carbide formation on the target surface with lower sputter yield similar to compound formation on the metallic target for reactive sputtering with oxygen and nitrogen [33,34]. However, in the case of $\mathrm{CH}_{4} / \mathrm{Ar}$ system, an additional carbon layer may further form with the carbide layer on the target surface under a high $\mathrm{CH}_{4}$ condition. As the carbon layer has a higher sputter yield than carbide, it may raise the deposition rate for further increasing the $\mathrm{CH}_{4}$ ratio from $5 \%$ to $6 \%[35,36]$.
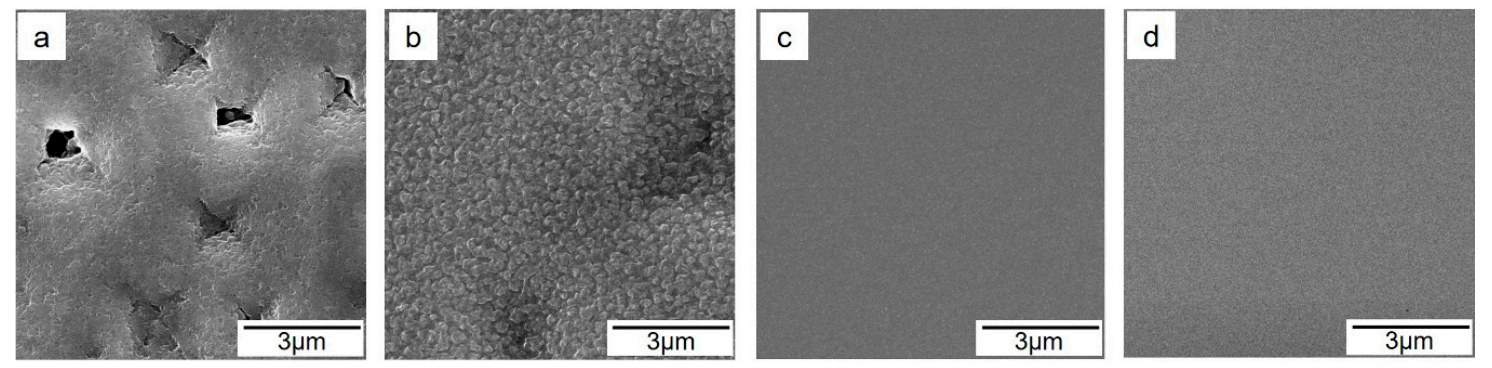

Figure 5. Scanning electron microscopy (SEM) micrographs of the samples grown with different $\mathrm{CH}_{4}$ flow ratios. (a) $3 \%$, (b) $4 \%$, (c) $5 \%$, and (d) $6 \%$.

For the samples deposited with $3 \%$ and $4 \% \mathrm{CH}_{4}$, XPS spectra for $\mathrm{C}-1 \mathrm{~s}$ and Ti-2p after sputtering etching for $6.5 \mathrm{~min}$ are shown in Figure 6. In Figure 6a, the C-1s peak of binding energy at $281.6 \mathrm{eV}$ can be attributed to the $\mathrm{Ti}-\mathrm{C}$ bonds in $\mathrm{TiC}$, and the absence of $\mathrm{sp}^{2} \mathrm{C}$ peak at $284.6 \mathrm{eV}$ clearly indicates that formation of graphitic and amorphous carbon phases in the deposited film can be neglected. In Figure $6 \mathrm{~b}$, the Ti $2 \mathrm{p}_{3 / 2}$ and $2 \mathrm{p}_{1 / 2}$ peaks can be deconvoluted into those of metallic Ti and TiC after curve fitting as the following. The peaks at $453.8 \mathrm{eV}$ and $454.6 \mathrm{eV}$ represent Ti-2 $\mathrm{p}_{3 / 2}$ from metallic $\mathrm{Ti}$ and $\mathrm{TiC}$, and the peaks at $459.8 \mathrm{eV}$ and $460.6 \mathrm{eV}$ are associated to Ti-2 $\mathrm{p}_{1 / 2}$ from metallic Ti and $\mathrm{TiC}[37,38]$, respectively. The results confirm the presence of metallic Ti in the deposited films for $3 \%$ and $4 \% \mathrm{CH}_{4}$ conditions shown in the above XRD results. Also, several studies have reported that the 
Ti $2 p_{3 / 2}$ binding energy of $\operatorname{TiC}_{x}(x=0.86-0.97)$ increases with increasing $x[39,40]$. With respect to the binding energies of metallic $\mathrm{Ti}$, the shift of $2 \mathrm{p}_{3 / 2}$ binding energies in $\mathrm{TiC}_{x}$ is shown to be $0.8 \mathrm{eV}$ for both of $3 \%$ and $4 \% \mathrm{CH}_{4}$ conditions, which can be corresponding to $x=0.95$.
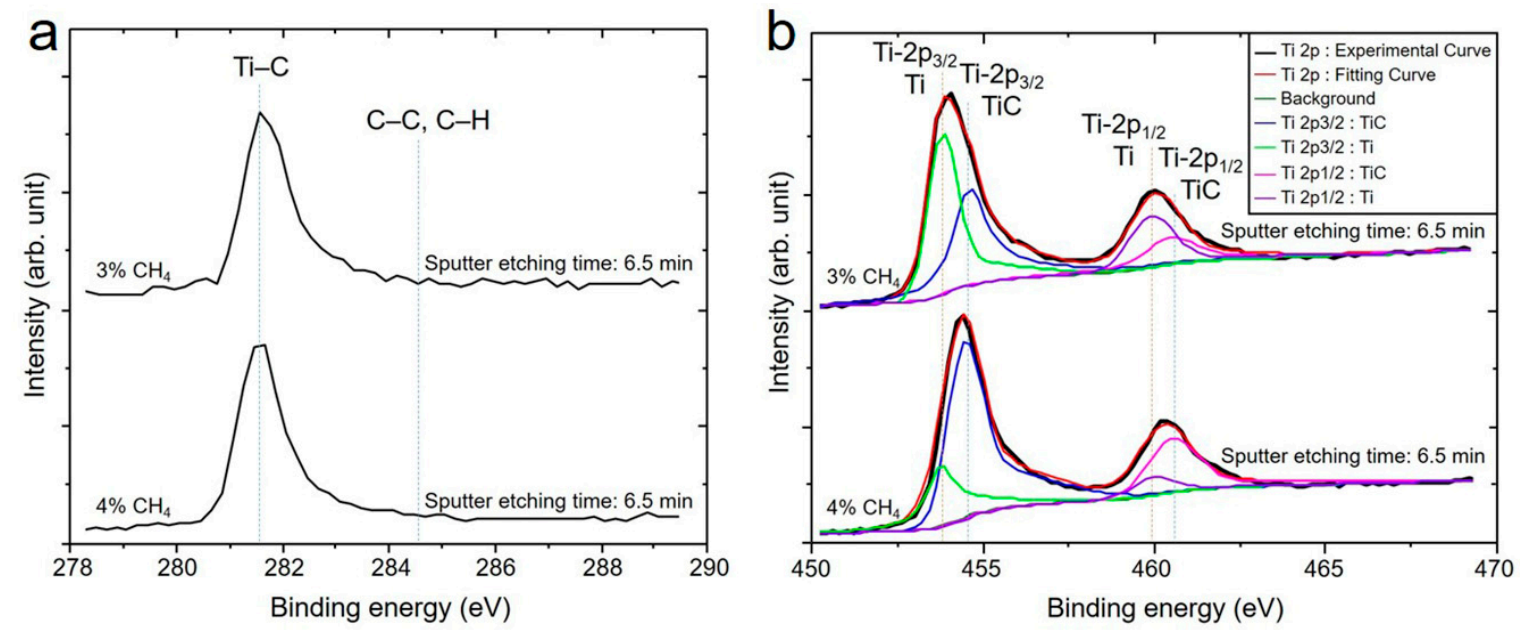

Figure 6. X-ray photoelectron spectroscopy (XPS) spectra for (a) C-1s and (b) Ti-2p after sputter etching for $6.5 \mathrm{~min}$. The intensity has been normalized.

For $5 \%$ and $6 \% \mathrm{CH}_{4}$ conditions, the XPS results can show that the deposited films are fully consisted of $\mathrm{TiC}$ as shown in Figure 7 for the depth profile and spectra of $\mathrm{C}$, $\mathrm{Ti}$, and $\mathrm{Si}$ obtained at different depth (6\% not shown). The XPS depth profile in Figure 7a shows that nearly $43 \%$ oxygen concentration on the surface, suggesting that $\mathrm{TiC}$ has been partially oxidized. The thickness of the surface oxide is estimated to be less than $5 \mathrm{~nm}$. The [C]/[Ti] ratio in relative atomic fraction is almost constant with depth in the film, implying that the film composition is uniform. Figure $7 \mathrm{~b}-\mathrm{d}$ show $\mathrm{C}-1 \mathrm{~s}$, Ti-2p, and Si-2p XPS spectra from the same sample with different sputter etching time corresponding to different depths. In Figure $7 \mathrm{~b}$, the $\mathrm{C}-1 \mathrm{~s}$ spectra for $5 \% \mathrm{CH}_{4}$ show the same characteristic of Ti-C binding energy at $281.6 \mathrm{eV}$ as those of the $3 \%$ and $4 \% \mathrm{CH}_{4}$ samples (Figure $6 \mathrm{a}$ ), suggesting that only the TiC phase is present in the film without graphitic and amorphous carbon phases. In Figure 7c, the Ti-2p spectrum obtained before surface cleaning exhibits two groups of Ti-2 $\mathrm{p}_{3 / 2}$ and Ti-2 $\mathrm{p}_{1 / 2}$. In addition to the binding energies at 454.6 and $460.6 \mathrm{eV}$ for Ti-C bonds in TiC, the Ti- $2 \mathrm{p}_{3 / 2}$ component at $458.6 \mathrm{eV}$ corresponds to Ti-O bond in $\mathrm{TiO}_{2}$, and it is not observed after Ar sputtering for $0.5 \mathrm{~min}$ [41,42]. The co-existence of both $\mathrm{TiO}_{2}$ and $\mathrm{TiC}$ on the film surface suggests that the $\mathrm{TiC}$ film has been partially oxidized after exposure to air. Moreover, all the Ti binding energies in the spectra obtained after Ar sputtering for $0.5 \mathrm{~min}$ and $12.8 \mathrm{~min}$ can be attributed to $\mathrm{TiC}$ instead of metallic Ti. The evidence supports the XRD results that the film consists of TiC phase only. The Si-2p spectrum recorded around the interface (after $12.8 \mathrm{~min}$ of sputter etching) as shown in Figure 7d, reveals only one peak at $99.2 \mathrm{eV}$ which corresponds to $\mathrm{Si}-\mathrm{Si}$ binding energy without $\mathrm{Si}-\mathrm{C}$ one, suggesting that no $\mathrm{SiO}_{2}$, $\mathrm{SiC}$, Ti silicide, and TiSiC form at the TiC/Si interface. Compared with standard formation enthalpy of $\beta-\mathrm{SiC}\left(\Delta \mathrm{H}_{298}=-28.03 \mathrm{~kJ} / \mathrm{mol}\right)$, it can be understood that TiC $\left(\Delta \mathrm{H}_{298}=-184.6 \mathrm{~kJ} / \mathrm{mol}\right)$ is more thermodynamically stable $[26,43]$. In addition, it has been reported that the formation of $\mathrm{Ti}_{5} \mathrm{Si}_{3}$ and $\mathrm{Ti}_{3} \mathrm{SiC}_{2}$ often occurs above $1000{ }^{\circ} \mathrm{C}[44,45]$. Therefore, no binding signals from SiC and Ti-related silicide at the TiC/Si interface can be observed in XPS spectra shown above. 

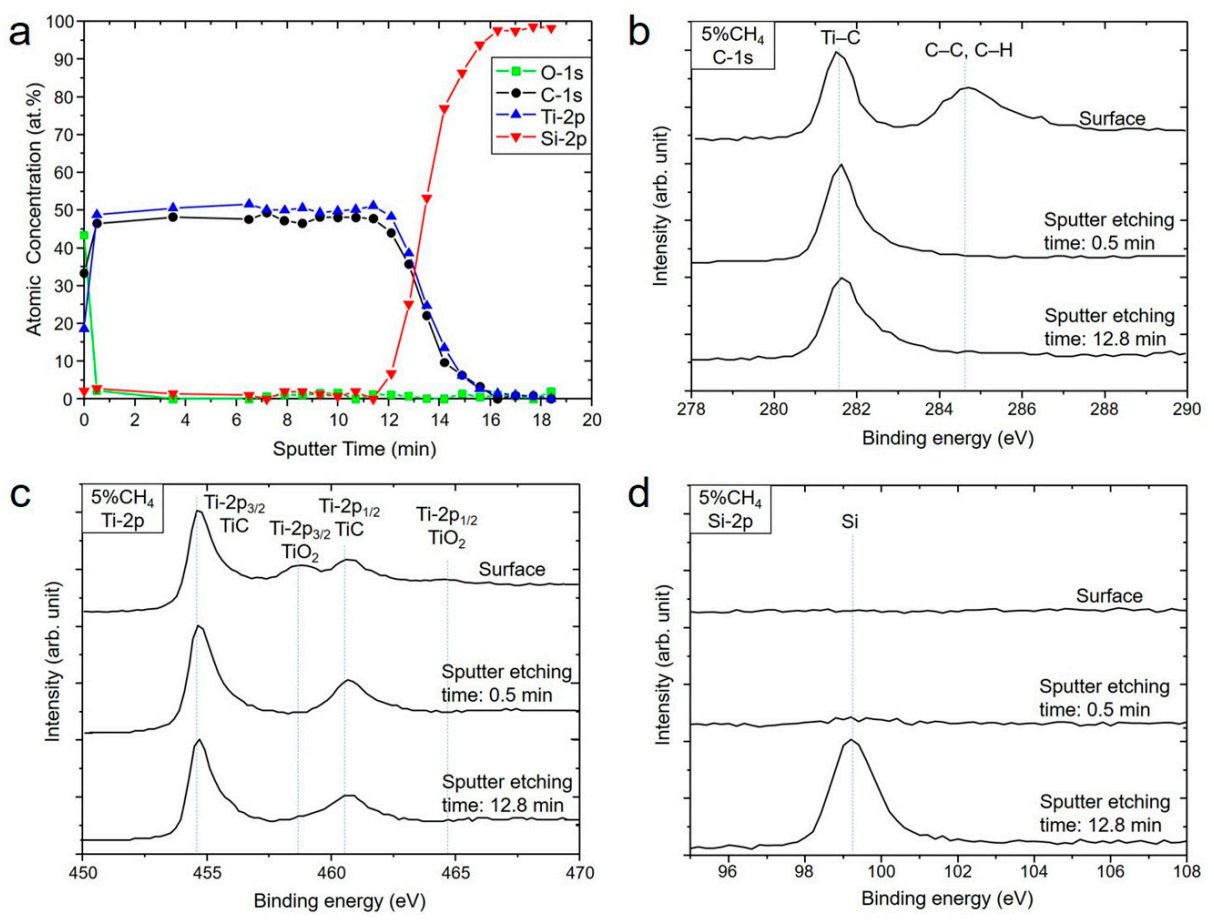

Figure 7. XPS data for $5 \% \mathrm{CH}_{4}$. (a) Depth profile, and spectra showing (b) C-1s, (c) Ti-2p, and (d) Si-2p at different depth in the TiC film. The intensity has been normalized.

From the XPS results obtained from all the films, the elemental compositions of the TiC films in relative atomic fraction versus $\mathrm{CH}_{4}$ flow ratio are presented in Figure 8. The atomic fraction of titanium [Ti] for metallic $\mathrm{Ti}$ and $\mathrm{TiC}$ was determined from the ratio of the integrated intensity for Ti- $2 \mathrm{p}_{3 / 2}$ peaks in Figure 6. The relative [C]/[Ti] ratio is nearly close to $1 \mathrm{in} \mathrm{TiC}$, and the [Ti] of metallic Ti decreases and disappears with increasing the $\mathrm{CH}_{4}$ ratio from $3 \%$ to $6 \%$. The higher $[\mathrm{C}] /[\mathrm{Ti}]$ ratio for $6 \% \mathrm{CH}_{4}$ than that for $5 \% \mathrm{CH}_{4}$ is consistent with the composition deduced from lattice parameter. From the above results, formation of $\mathrm{TiC}$ by sputtering deposition requires a $\mathrm{CH}_{4}$-rich condition, and more $\mathrm{CH}_{4}$ can result in higher stoichiometry (i.e., increase in $x$ ).

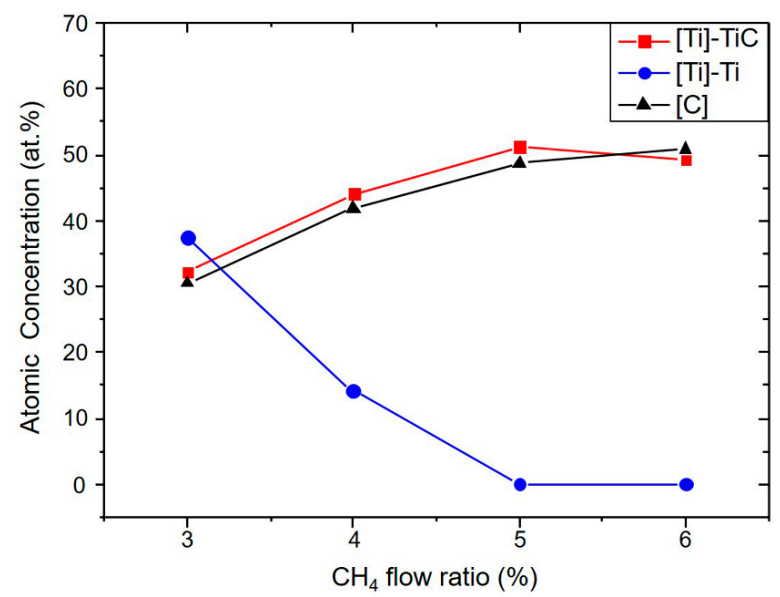

Figure 8. Relative atomic concentration of $\mathrm{Ti}$ and $\mathrm{C}$ in deposited films as a function of $\mathrm{CH}_{4}$ flow ratio.

Figure 9 shows that the electrical resistivity of the film deposited with different $\mathrm{CH}_{4}$ flow ratio increases from 41 to $153 \mu \Omega \cdot \mathrm{cm}$ with increasing the $\mathrm{CH}_{4}$ ratio. The low resistivity is clearly due to the presence of the Ti metal as shown from the XPS and XRD results. Without metallic Ti, the film resistivity of TiC compound is above $120 \mu \Omega \cdot \mathrm{cm}$ similar to the values of epitaxial TiC film and single 
crystal TiC reported by $[23,46,47]$. Also, by comparison of the resistivities of both films deposited with $5 \%$ and $6 \% \mathrm{CH}_{4}$, it is shown that better film quality (lower XRC FWHM) results in a lower resistivity.

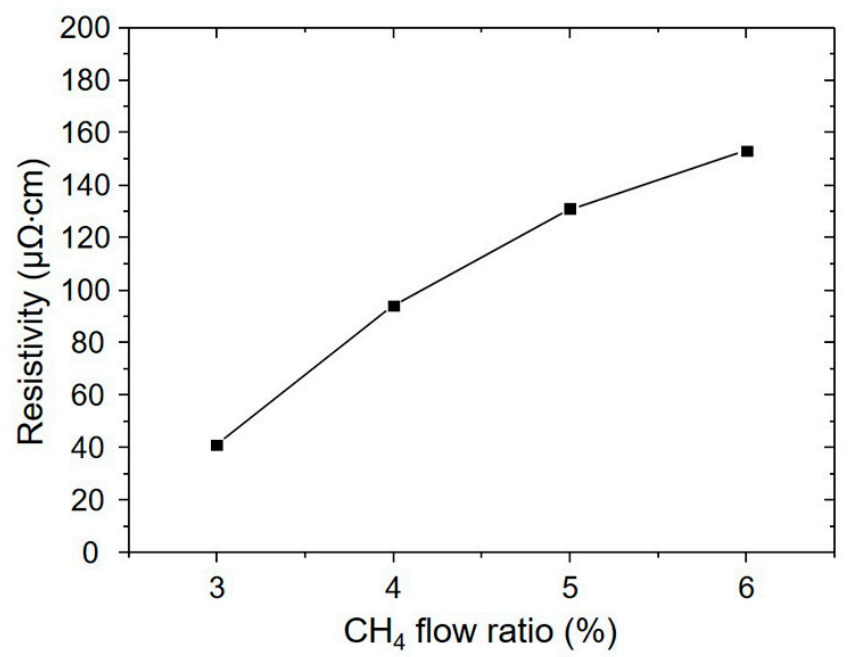

Figure 9. Electrical resistivity versus $\mathrm{CH}_{4}$ flow ratio.

\subsection{Evolution of Microstructure with Film Thickness}

The samples grown with $5 \% \mathrm{CH}_{4}$ which exhibit better crystallinity are chosen for further study of the effect of film thickness on the microstructure. For the sample with deposition time for $6 \mathrm{~min}$, the XRD 20- $\omega$ pattern (not shown) is similar to that of the sample for 15 min deposition in Figure 1, exhibiting only 200 and $400 \mathrm{TiC}$ reflections, and the $\phi$-scan shows $\mathrm{TiC}$ in epitaxy with $\mathrm{Si}$ as well. Furthermore, the measured TiC (200) XRC FWHM is $1.95^{\circ}$, and the electrical resistivity is $97 \mu \Omega \cdot \mathrm{cm}$. Figure 10a shows a typical cross-sectional bright field (BF) TEM image taken along the Si [011] zone axis from the $6 \mathrm{~min}$ sample. From image contrast, three layers corresponding to the surface coating of $\mathrm{C}$ and $\mathrm{Pt}, \mathrm{TiC}$, and Si from top to bottom can be clearly identified, respectively. The thickness of $\mathrm{TiC}$ is approximately $50 \mathrm{~nm}$, which gives an average deposition rate about $8 \mathrm{~nm} / \mathrm{min}$. The image contrast in the TiC film is uniform, implying that TiC of the whole area is grown in the same orientation. Figure $10 \mathrm{~b}$ is a typical annular dark field (ADF) STEM image (Z-contrast) of the TiC/Si interface in atomic resolution (enlarged from the red framed region in Figure 10a) after applying the Wiener filter to reduce image noise. It shows the Z-contrast across the TiC/Si interface, where the bright and gray dots correspond to $\mathrm{Ti}$ and $\mathrm{Si}$ atomic columns, respectively. The projected atomic configurations of $\mathrm{TiC}$ and $\mathrm{Si}$ structure models are also illustrated in the image. As can be seen, the TiC/Si interface structure is seen to be flat with steps of one and two atomic layers. According to the arrangement of Ti and $\mathrm{Si}$ atomic columns in the ADF-STEM image, five $\{022\}$ spacings (Ti atomic columns) in TiC match with four $\{022\}$ spacings in $\mathrm{Si}$ as the white lines drawn in Figure 10b. Thus, even though there is a large lattice mismatch of about $20 \%$ between TiC [011] $\left(d_{011}=3.071 \AA\right)$ and Si [011] $\left(d_{011}=3.840 \AA\right)$, the epitaxial growth of $\mathrm{TiC}$ on $\mathrm{Si}$ can be reasoned with DME [24] in the ratio close to 5/4. Figure 10c shows the fast Fourier transform (FFT) patterns from $\mathrm{TiC}$ and $\mathrm{Si}$, indicating $\mathrm{TiC}[0 \overline{1} 1] / / \mathrm{Si}[0 \overline{1} 1]$ with $\mathrm{TiC}(100) / / \mathrm{Si}(100)$ in consistence with the epitaxial relationship deduced from the XRD results.

Figure 11a presents a typical cross-sectional BF TEM image of the sample with deposition time for $15 \mathrm{~min}$. The thickness of TiC layer is about $130 \mathrm{~nm}$. For the film growth to about $50 \mathrm{~nm}$ thickness, the image contrast and atomic resolution ADF-STEM image observations near the TiC/Si interface (not shown) exhibit similar characteristics to those shown in Figure 10. However, for the film regions above $50 \mathrm{~nm}$ thickness, it is clearly seen that diffraction contrast of the image in the TiC layer are varied. The bright regions in a shape like an inverted triangle may be highly tilt or misoriented grains of TiC for which they do not show any reflections in the XRD pattern. In Figure 11b, a typical high resolution TEM image obtained from one of such grains as shown in Figure 11 with the corresponding 
FFT pattern (Figure 11c) illustrates that it is in an orientation approximately inclined with $\sim 15^{\circ}$ from $<111>$. Such highly misoriented grains may not be observed in the XRD patterns. The appearance of those misoriented grains after growth of a thicker film can be reasoned with relaxation of increased stresses in the film [48-53]. It has been often observed in growth of $<100>$ transition metal nitrides of rock salt structure including TiN for which formation of $<111>$ oriented grains occurs after a thicker film is grown with the accumulated film stress in a large extent [54-56]. Therefore, the higher electrical resistivity of the thicker film is likely caused by those misoriented grains.

a

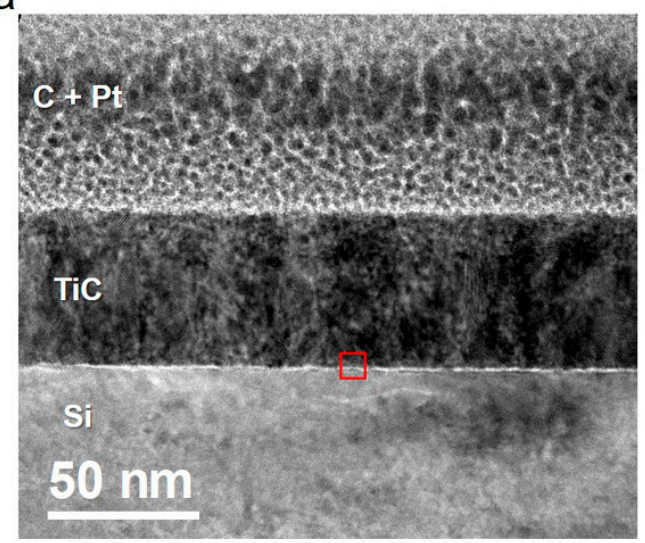

b

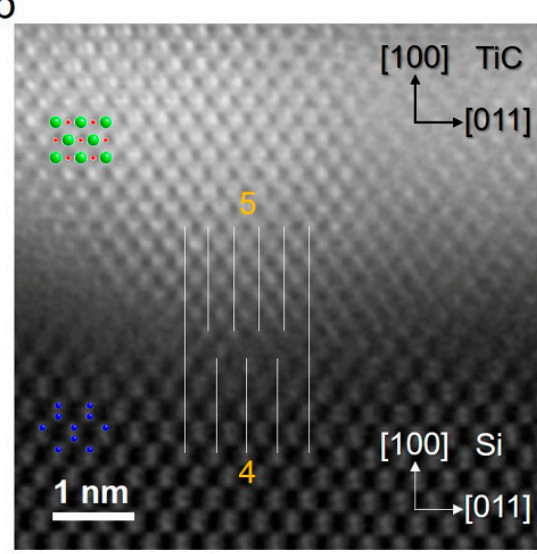

C

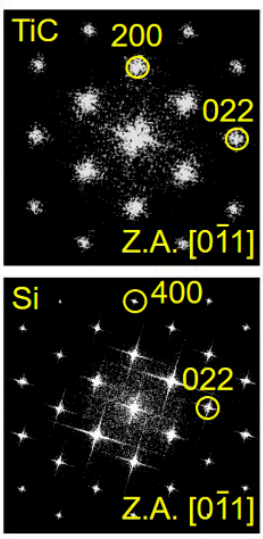

Figure 10. (a) Cross-sectional BF TEM image of the TiC layer on $\mathrm{Si}$ for the $5 \% \mathrm{CH}_{4} / 6$ min sample; (b) Atomic resolution scanning transmission electron microscopy (STEM)-ADF image of the TiC/Si interface (the red box in Figure 10a) (after Wiener filtering) showing Z-contrast. Bright and gray dots correspond to $\mathrm{Ti}$ and $\mathrm{Si}$ atomic columns, respectively. Projected atomic configurations of TiC and Si structure models are shown in the image. The white lines illustrating the domain matching epitaxy (DME) relationship with 5/4 ratio. Zone axis // TiC [0 $\overline{1} 1] / /$ Si [0 $\overline{1} 1]$; and (c) fast Fourier transform (FFT) patterns of $\mathrm{TiC}$ and $\mathrm{Si}$.

a

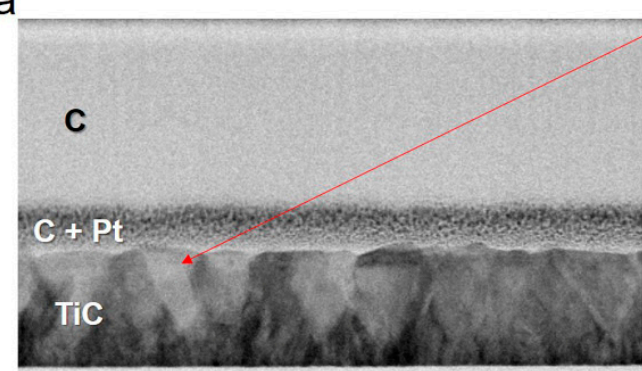

Si

$100 \mathrm{~nm}$ b

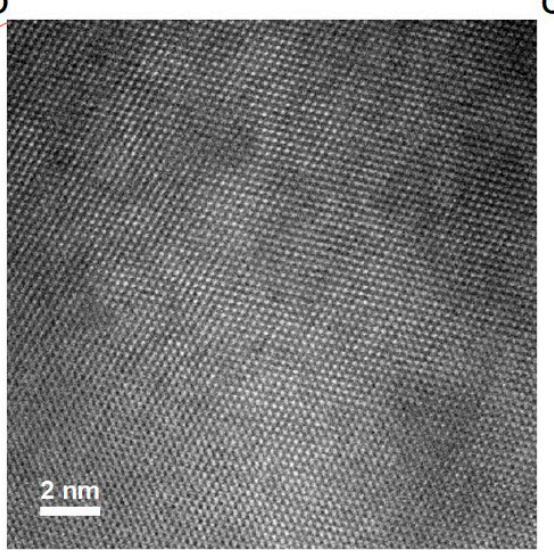

C

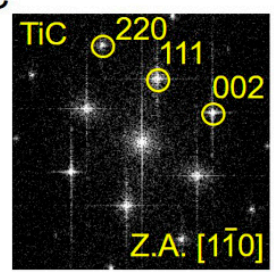

Figure 11. (a) Cross-sectional bright field (BF) STEM image of the TiC layer on $\mathrm{Si}$ for the $5 \% \mathrm{CH}_{4} / 15$ min sample; (b) STEM-ADF image from a top bright disoriented grain in (a) with the FFT pattern shown in (c).

\section{Conclusions}

Heteroepitaxial growth of TiC film on $\mathrm{Si}(100)$ substrate can be achieved by DC reactive magnetron sputtering with $3 \%-6 \% \mathrm{CH}_{4}$ in Ar. A cube-on-cube epitaxial relationship of $\mathrm{TiC}(100)[0 \overline{1} 1] / / \mathrm{Si}$ (100)[011] exists between $\mathrm{TiC}$ and Si with $5 / 4$ ratio for domain match across the interface. The relatively smooth surface morphology can be obtained by increasing $\mathrm{CH}_{4}$ flow ratio. At lower $\mathrm{CH}_{4}$ flow ratio, the metallic hcp Ti phase is present in the deposited films which can have a resistivity as low as $41 \mu \Omega \cdot \mathrm{cm}$, 
and it is not observed for growth with high $\mathrm{CH}_{4}$ flow ratio which results in the fully formed TiC films exhibiting a high resistivity more than $120 \mu \Omega \cdot \mathrm{cm}$. Also, the crystalline qualities of epitaxial TiC can be improved by increasing the $\mathrm{CH}_{4}$ flow ratio as shown with the XRC FWHM of TiC (200) from which for the film grown with $5 \% \mathrm{CH}_{4}$ exhibits the best quality with a minimum of $1.66^{\circ}$. For the film growth to the thickness exceeding $50 \mathrm{~nm}$, some highly misoriented TiC grains are observed.

Author Contributions: Conceptualization, Y.-S.F. and L.C.; Data curation, Y.-S.F., K.-A.C., and W.-C.C.; Formal analysis, Y.-S.F., T.H.D. and K.-A.C.; Funding Acquisition, W.-C.C. and L.C.; Methodology, Y.-S.F.; Software, T.H.D.; Supervision, L.C.; Validation, Y.-S.F.; Writing—original draft, Y.-S.F.; Writing-review \& editing, L.C. All authors have read and agreed to the published version of the manuscript.

Funding: This work was supported by the Ministry of Science and Technology Taiwan, R.O.C. under contract of MOST 107-2221-E-009-009-MY2, 108-2221-E-492-017, and 108-2622-E-492-029-CC3.

Conflicts of Interest: The authors declare no conflict of interest.

\section{References}

1. Pierson, H.O. Handbook of Refractory Carbides and Nitrides; Noyes Press: Park Ridge, NJ, USA, 1996; pp. 71-72.

2. Perry, D.L. Handbook of Inorganic Compounds, 2nd ed.; CRC Press: Boca Raton, FL, USA, 2011; p. 431.

3. Lipatnikov, V.N.; Zueva, L.V.; Gusev, A.I.; Kottar, A. Disorder-order phase transformations and electrical resistivity of nonstoichiometric titanium carbide. Phys. Solid State 1998, 40, 1211-1218. [CrossRef]

4. Oakes, J.J. A comparative evaluation of $\mathrm{HfN}, \mathrm{Al}_{2} \mathrm{O}_{3}, \mathrm{TiC}$ and $\mathrm{TiN}$ coatings on cemented carbide tools. Thin Solid Films 1983, 108, 173. [CrossRef]

5. Boving, H.J.; Zintermann, H.E. Wear-resistant hard titanium carbide coatings for space applications. Tribol. Int. 1990, 23, 129-133. [CrossRef]

6. Shanaghi, A.; Chu, P.K.; Rouhaghdam, A.R.S.; Xu, R.; Hu, T. Structure and corrosion resistance of Ti/TiC coatings fabricated by plasma immersion ion implantation and deposition on nickel-titanium. Surf. Coat. Technol. 2013, 229, 151-155. [CrossRef]

7. Palma, R.H.; Sepúlveda, A.H.; Espinoza, R.A.; Montiglio, R.C. Performance of Cu-TiC alloy electrodes developed by reaction milling for electrical-resistance welding. J. Mater. Process. Technol. 2005, 169, $62-66$. [CrossRef]

8. Gao, Y.; Presser, V.; Zhang, L.; Niu, J.J.; McDonough, J.K.; Pérez, C.R.; Lin, H.; Fong, H.; Gogotsi, Y. High power supercapacitor electrodes based on flexible TiC-CDC nano-felts. J. Power Sources 2012, 201, 368-375. [CrossRef]

9. Pan, L.; Shoji, T.; Nagataki, A.; Nakayama, Y. Field emission properties of titanium carbide coated carbon nanotube arrays. Adv. Eng. Mater. 2007, 9, 584-587. [CrossRef]

10. Qin, Y.; Hu, M. Characterization and field emission characteristics of carbon nanotubes modified by titanium carbide. Appl. Surf. Sci. 2008, 254, 3313-3317. [CrossRef]

11. Lee, S.-K.; Zetterling, C.-M.; Östling, M.; Palmquist, J.-P.; Jansson, U. Low resistivity ohmic contacts on 4H-silicon carbide for high power and high temperature device applications. Microelectron. Eng. 2002, 60, 261-268. [CrossRef]

12. Wilhelmsson, O.; Palmquist, J.-P.; Lewin, E.; Emmerlich, J.; Eklund, P.; Persson, P.O.A.; Hogberg, H.; Li, S.; Ahuja, R.; Eriksson, O.; et al. Deposition and characterization of ternary thin films within the Ti-Al-C system by DC magnetron sputtering. J. Cryst. Growth 2006, 291, 290-300. [CrossRef]

13. Palmquist, J.-P.; Jansson, U.; Seppänen, T.; Persson, P.O.A.; Birch, J.; Hultman, L.; Isberg, P. Magnetron sputtered epitaxial single-phase $\mathrm{Ti}_{3} \mathrm{SiC}_{2}$ thin films. Appl. Phys. Lett. 2002, 81, 835. [CrossRef]

14. Eklund, P.; Högberg, H.; Hultman, L. Epitaxial TiC/SiC multilayers. Phys. Status Solidi Rapid Res. Lett. 2007, 1, 113-115. [CrossRef]

15. Zhao, Y.; Wang, Y.; Cheng, X.; Dong, L.; Zhang, Y.; Zang, J. Platinum nanoparticles supported on epitaxial $\mathrm{TiC} /$ nanodiamond as an electrocatalyst with enhanced durability for fuel cells. Carbon 2014, 67, 409-416. [CrossRef]

16. Zhao, Q.H.; Parsons, J.D.; Chen, H.S.; Chaddha, A.K.; Wu, J.; Kruaval, G.B.; Downham, D. Single crystal titanium carbide, epitaxially grown on zincblend and wurtzite structures of silicon carbide. Mater. Res. Bull. 1995, 30, 761-769. [CrossRef] 
17. Qi, Q.; Zhang, W.Z.; Shi, L.Q.; Zhang, W.Y.; Zhang, W.; Zhang, B. Preparation of single-crystal TiC (111) by radio frequency magnetron sputtering at low temperature. Thin Solid Films 2012, 520, 6882-6887. [CrossRef]

18. Braic, M.; Zoita, N.C.; Danila, M.; Grigorescu, C.E.A.; Logofatu, C. Hetero-epitaxial growth of TiC films on $\mathrm{MgO}(001)$ at $100{ }^{\circ} \mathrm{C}$ by DC reactive magnetron sputtering. Thin Solid Films 2015, 589, 590-596. [CrossRef]

19. Ferro, D.; Rau, J.V.; Albertini, V.R.; Generosi, A.; Teghil, R.; Barinov, S.M. Pulsed laser deposited hard TiC, $\mathrm{ZrC}, \mathrm{HfC}$ and $\mathrm{TaC}$ films on titanium: Hardness and an energy dispersive X-ray diffraction study. Surf. Coat. Technol. 2008, 202, 1455-1461. [CrossRef]

20. Norin, L.; McGinnis, S.; Jansson, U.; Carlsson, J.-O. Low temperature deposition of epitaxial titanium carbide on $\mathrm{MgO}$ (001) by co-evaporation of C60 and Ti. J. Vac. Sci. Technol. A 1997, 15, 3082. [CrossRef]

21. Archer, N.J. The plasma-assisted chemical vapour deposition of TiC, $\mathrm{TiN}$ and $\mathrm{TiC}_{\mathrm{x}} \mathrm{N}_{1-\mathrm{x}}$. Thin Solid Films 1981, 80, 221-225. [CrossRef]

22. Sarkar, J. Sputtering Materials for VLSI and Thin Film Devices; William Andrew Publishing: Boston, MA, USA, 2010; pp. 93-170.

23. Zoita, N.C.; Braic, V.; Danila, M.; Vlaicu, A.M.; Logofatu, C.; Grigorescu, C.E.A.; Braic, M. Influence of film thickness on the morphological and electrical properties of epitaxial TiC films deposited by reactive magnetron sputtering on MgO substrates. J. Cryst. Growth 2014, 389, 92-98. [CrossRef]

24. Narayan, J.; Larson, B.C. Domain epitaxy: A unified paradigm for thin film growth. J. Appl. Phys. 2003, 93, 278. [CrossRef]

25. Sheu, W.-H.; Wu, S.-T. Epitaxial Growth of TiC (002) on Si (001) by Reactive Magnetron Sputtering at Low Temperatures. Jpn. J. Appl. Phys. 1998, 37, 6094-6097. [CrossRef]

26. Haase, V.; Kirschstein, G.; List, H.; Ruprecht, S.; Sangster, R.; Schröder, F.; Töpper, W.; Vanecek, H.; Heit, W.; Schlichting, J. Gmelin Handbook of Inorganic and Organometallic Chemistry: Si Silicon; Springer: Berlin/Heidelberg, Germany, 1985; pp. 1-5.

27. Wakelkamp, W.J.J.; van Loo, F.J.J.; Metselaar, R. Phase Relations in the Ti-Si-C System. J. Eur. Ceram. Soc. 1991, 8, 135-139. [CrossRef]

28. Bandyopadhyay, D. The Ti-Si-C system (Titanium-Silicon-Carbon). J. Phase Equilibria Diffus. 2004, 25, 415-420. [CrossRef]

29. Gulbiński, W.; Mathur, S.; Shen,H.; Suszko, T.; Gilewicz, A.; Warcholiński, B. Evaluation of phase, composition, microstructure and properties in TiC/a-C:H thin films deposited by magnetron sputtering. Appl. Surf. Sci. 2005, 239, 302-310. [CrossRef]

30. Riley, D.P.; Connor, D.J.O.; Dastoor, P.; Brack, N.; Pigram, P.J. Comparative analysis of $\mathrm{Ti}_{3} \mathrm{SiC}_{2}$ and associated compounds using X-ray diffraction and X-ray photoelectron spectroscopy. J. Phys. D 2002, 35, 1603. [CrossRef]

31. Shin, C.-S.; Gall, D.; Kim, Y.-W.; Desjardins, P.; Petrov, I.; Greene, J.E. Epitaxial NaCl structure $\delta$-TaN $\mathrm{T}_{\mathrm{x}}(001)$ : Electronic transport properties, elastic modulus, and hardness versus N/Ta ratio. J. Appl. Phys. 2001, 90, 2879. [CrossRef]

32. Adachi, S. Properties of Semiconductor Alloys: Group-IV, III-V and II-VI Semiconductors; John Wiley \& Sons Ltd.: Gumma, Japan, 2009; p. 36.

33. Suhail, M.H.; Mohan Rao, G.; Mohan, S. Dc reactive magnetron sputtering of titanium-structural and optical characterization of $\mathrm{TiO}_{2}$ films. J. Appl. Phys. 1992, 71, 1421. [CrossRef]

34. Combadiere, L.; Machet, J. Study and control of both target-poisoning mechanisms and reactive phenomenon in reactive planar magnetron cathodic sputtering of TiN. Surf. Coat. Technol. 1996, 82, 145-157. [CrossRef]

35. Nyberga, T.; Högberg, H.; Greczynski, G.; Berg, S. A simple model for non-saturated reactive sputtering processes. Thin Solid Films 2019, 688, 137413. [CrossRef]

36. Sundgren, J.-E.; Johansson, B.-O.; Karlsson, S.-E. Mechanisms of reactive sputtering of titanium nitride and titanium carbide I: Influence of process parameters on film composition. Thin Solid Films 1983, 105, 353-366. [CrossRef]

37. Kisi, E.H.; Crossley, J.A.A.; Myhra, S.; Barsoum, M.W. Structure and crystal chemistry of $\mathrm{Ti}_{3} \mathrm{SiC}_{2}$. J. Phys. Chem. Solids 1998, 59, 1437-1443. [CrossRef]

38. Chan, C.-M.; Trigwell, S.; Duerig, T. Oxidation of an NiTi alloy. Surf. Interface Anal. 1990, 15, 349-354. [CrossRef] 
39. Johansson, L.I.; Hagström, A.L.; Jacobson, B.E.; Hagström, S.B.M. ESCA studies of core level shifts and valence band structure in nonstoichiometric single crystals of titanium carbide. J. Electron Spectros. Relat. Phenom. 1977, 10, 259-271. [CrossRef]

40. Ramqvist, L.; Ekstig, B.; Källne, E.; Noreland, E.; Manne, R. X-ray study of inner level shifts and band structure of TiC and related compounds. J. Phys. Chem. Solids 1969, 30, 1849-1860. [CrossRef]

41. Liu, B.; Zhao, X.; Zhao, Q.; Li, C.; He, X. The effect of $\mathrm{O}_{2}$ partial pressure on the structure and photocatalytic property of $\mathrm{TiO}_{2}$ films prepared by sputtering. Mater. Chem. Phys. 2005, 90, 207-212. [CrossRef]

42. Biesinger, M.C.; Lau, L.W.M.; Gerson, A.R.; Smart, R.S.C. Resolving surface chemical states in XPS analysis of first row transition metals, oxides and hydroxides: Sc, Ti, V., Cu and Zn. Appl. Surf. Sci. 2010, 257, 887-898. [CrossRef]

43. Holt, J.B.; Munir, Z.A. Combustion synthesis of titanium carbide: Theory and experiment. J. Mater. Sci. 1986, 21, 251-259. [CrossRef]

44. Barsoum, M.W. The MN+1AXN phases: A new class of solids: Thermodynamically stable nanolaminates. Prog. Solid State Chem. 2000, 28, 201-281. [CrossRef]

45. Yang, S.; Sun, Z.M.; Hashimoto, H. Synthesis of $\mathrm{Ti}_{3} \mathrm{SiC}_{2}$ powder from $1 \mathrm{Ti} /(1+\mathrm{x}) \mathrm{Si} / 2 \mathrm{TiC}$ powder mixtures. J. Alloys Compd. 2004, 368, 318-325. [CrossRef]

46. Otani, S.; Tanaka, T.; Ishizawa, Y. Electrical resistivities in single crystals of $\mathrm{TiC}_{\mathrm{x}}$ and $\mathrm{VC}_{\mathrm{x}}$. J. Mater. Sci. 1986, 21, 1001-1014. [CrossRef]

47. Morelli, D.T. Thermal conductivity and thermoelectric power of titanium carbide single crystals. Phys. Rev. B 1991, 44, 5453-5458. [CrossRef]

48. Petrov, I.; Barna, P.B.; Hultman, L.; Greene, J.E. Microstructural evolution during film growth. J. Vac. Sci. Technol. A 2003, 21, 117-128. [CrossRef]

49. McKenzie, D.R.; Bilek, M.M.M. Electron diffraction from polycrystalline materials showing stress induced preferred orientation. J. Appl. Phys. 1999, 86, 230-236. [CrossRef]

50. Djafer, A.Z.A.; Saoula, N.; Madaoui, N.; Zerizer, A. Deposition and characterization of titanium carbide thin films by magnetron sputtering using Ti and TiC targets. Appl. Surf. Sci. 2014, 312, 57-62. [CrossRef]

51. Wang, H.; Zhang, S.; Li, Y.; Sun, D. Bias effect on microstructure and mechanical properties of magnetron sputtered nanocrystalline titanium carbide thin films. Thin Solid Films 2008, 516, 5419-5423. [CrossRef]

52. Su, Y.; Wang, X.; Wang, H.; Wen, M.; Zheng, W. Grain-size effect on the preferred orientation of TiC/ $\alpha-\mathrm{C}: \mathrm{H}$ thin films. Appl. Surf. Sci. 2012, 258, 6800-6806. [CrossRef]

53. Lee, C.W.; Nam, S.W.; Chun, J.S. Effect of experimental parameters on the preferred orientation of chemically vapor deposited TiC on cemented carbides. J. Vac. Sci. Technol. 1982, 21, 42-46. [CrossRef]

54. Pelleg, J.; Zevin, L.Z.; Lungo, S.; Croitoru, N. Reactive-sputter-deposited TiN films on glass substrates. Thin Solid Films 1991, 197, 117-128. [CrossRef]

55. Oh, U.C.; Je, J.H. Effects of strain energy on the preferred orientation of TiN thin films. J. Appl. Phys. 1993, 74, 1692. [CrossRef]

56. Je, J.H.; Noh, D.Y.; Kim, H.K.; Liang, K.S. Preferred orientation of TiN films studied by a real time synchrotron X-ray scattering. J. Appl. Phys. 1997, 81, 1692. [CrossRef]

(C) 2020 by the authors. Licensee MDPI, Basel, Switzerland. This article is an open access article distributed under the terms and conditions of the Creative Commons Attribution (CC BY) license (http://creativecommons.org/licenses/by/4.0/). 